\title{
Comparison of enzymatic activities and proteomic profiles of Butyrivibrio fibrisolvens grown on different carbon sources
}

\author{
Hana Sechovcová ${ }^{1,5^{*}}$ D, Lucie Kulhavá ${ }^{2,4}$, Kateřina Fliegerová ${ }^{1}$, Mária Trundová ${ }^{3}$, Daniel Morais ${ }^{6}$, Jakub Mrázek and
} Jan Kopečný

\begin{abstract}
Background: The rumen microbiota is one of the most complex consortia of anaerobes, involving archaea, bacteria, protozoa, fungi and phages. They are very effective at utilizing plant polysaccharides, especially cellulose and hemicelluloses. The most important hemicellulose decomposers are clustered with the genus Butyrivibrio. As the related species differ in their range of hydrolytic activities and substrate preferences, Butyrivibrio fibrisolvens was selected as one of the most effective isolates and thus suitable for proteomic studies on substrate comparisons in the extracellular fraction. The B. fibrisolvens genome is the biggest in the butyrivibria cluster and is focused on "environmental information processing" and "carbohydrate metabolism".

Methods: The study of the effect of carbon source on B. fibrisolvens 3071 was based on cultures grown on four substrates: xylose, glucose, xylan, xylan with $25 \%$ glucose. The enzymatic activities were studied by spectrophotometric and zymogram methods. Proteomic study was based on genomics, 2D electrophoresis and nLC/MS (Bruker Daltonics) analysis.

Results: Extracellular $\beta$-endoxylanase as well as xylan $\beta$-xylosidase activities were induced with xylan. The presence of the xylan polymer induced hemicellulolytic enzymes and increased the protein fraction in the interval from 40 to 80 kDa. 2D electrophoresis with $\mathrm{nLC} / \mathrm{MS}$ analysis of extracellular B. fibrisolvens 3071 proteins found 14 diverse proteins with significantly different expression on the tested substrates.

Conclusion: The comparison of four carbon sources resulted in the main significant changes in B. fibrisolvens proteome occurring outside the fibrolytic cluster of proteins. The affected proteins mainly belonged to the glycolysis and protein synthesis cluster.
\end{abstract}

Keywords: Butyrivibrio fibrisolvens, Proteomics, Rumen, Carbon sources

\section{Introduction}

B. fibrisolvens was isolated from rumen fluid in the mid-fifties by Bryant and Small [1]. It is a strictly anaerobic, non-spore-forming, monoflagellated, butyrate producing bacterium, which is a member of the family Lachnospiraceae (order Clostridiales, class Clostridia, phylum Firmicutes). This genus belongs to the core or

\footnotetext{
* Correspondence: sechovcova@iapg.cas.cz

${ }^{1}$ Institute of Animal Physiology and Genetics, CAS, v.v.i., Vídeňská 1083, 142 20 Prague, Czech Republic

${ }^{5}$ Department of Biochemistry and Microbiology, Faculty of Food and Biochemical Technology, University of Chemistry and Technology, Technická 5, 166286 Prague, Czech Republic

Full list of author information is available at the end of the article
}

heritable rumen species, which represent nearly half of the rumen population [2]. Together with the genera Ruminococcus, Butyrivibrio, and the Christensenellaceae family, all members of Firmicutes, they form an enriched rumen microbiota population in the prepartal period [3]. Butyrivibrio together with Pseudobutyrivibrio species also belong to the very first $25 \%$ colonizers of feed fibre [4]. The total numbers of both groups can amount to 0.6$2 \%$ of total bacterial counts [5]. In the colon, their levels fall to $0.001 \%$ [6]. Most strains can ferment various soluble sugars, disaccharides and oligosaccharides, producing butyrate as the major end product [7]. This feature makes Butyrivibrio strains an important component of digestive

(c) The Author(s). 2019 Open Access This article is distributed under the terms of the Creative Commons Attribution 4.0 International License (http://creativecommons.org/licenses/by/4.0/), which permits unrestricted use, distribution, and 
tract microbiota influencing the healthy state of colonocytes for which butyrate is the main energy source [8].

In the rumen, butyrivibria represent an important fibre degrader group which are able to utilize various hemicelluloses and xylans, pectin and starch, however exhibiting poor or no growth on cellulose [9]. In grasses, the predominant component of hemicellulose is arabinoxylan, containing $\beta(1 \rightarrow 4)$ linked xylose units, with $\alpha(1 \rightarrow 2)$ and $\alpha(1 \rightarrow 3)$ linked arabinose units with D-galactose, possibly D-glucose, as well as side chains of L-rhamnose [10]. The enzymes and genes involved in the decomposition of xylan by Butyrivibrio fibrisolvens strains have been thoroughly studied [11] and characterized after xylanase cloning and expression in E. coli [12] or after its purification from the culture medium [13]. Valuable data coming from the whole genome sequencing and proteome analysis has helped to supply the respective databases (UniProt, Cazy) with relevant information and create an integrated picture of the enzymatic map of this important bacterium for biomass conversion in ruminant animals.

The crucial enzymes of xylan hydrolysis are three types of endo- $\beta$-1,4-xylanases (EC 3.2.1.8) from GH family 10, 11,30 and two types of 1,4- $\beta$-xylosidases (EC 3.2.1.37) from GH family 1 and 43 [14]. Endo-xylanase of the GH 10 family requires two unsubstituted xylopyranose units, GH 11 family needs three xylopyranose units in row, and GH 30 family is a xylanohydrolase (glucuronoarabinoxylan endo- $\beta-1,4$-xylanase (EC 3.2.1.136)) acting on glucuronoxylan [15]. 1,4- $\beta$-xylosidase of family GH 43 is involved in xylooligosaccharide hydrolysis [16] and 1,4- $\beta$-xylosidase of family GH 1 splits off xyloside unit from the non-reducing end of xylan chain [17].

The utilization of hydrolytic products from hemicelluloses usually occurs under carbon catabolic repression (CCR), resulting in a preference for hexose over pentoses in bacteria [18]. The mechanism of simultaneous pentose and hexose utilization was observed in thermophilic G+ anaerobes (TGPA). An isolate of Thermoanaerobacter sp. utilized both hexose and pentose simultaneously. It was found that its glycobiome is organized into 13 modules (4-138 genes), and these genes are functionally coherent, presumably based on positive co-expression [19]. In Butyrivibrio species, both CCR and simultaneous metabolism were observed. The type strain of B. fibrisolvens 3071 is able to utilize xylose and glucose simultaneously [20]. Therefore these substrates were chosen for this proteomic study.

Nowadays, molecular methods for fibre degradation including genomics and proteomics are preferred to obtain a deep understanding of the digestion process [21]. Among ruminal xylanolytic bacteria, advanced proteomic and mass spectrometric methods for exploring xylan degradation have been used exclusively for $B$. proteoclasticus. Its complete genome sequence [22] together with the studies of its extracellular polysaccharide-degrading proteome, its cytosolic oligosaccharide-degrading proteome $[23,24]$ and its carbohydrate transporting membrane proteins [25] substantially expanded current knowledge about the hydrolytic capability of the $B$. proteoclasticus type strain $\mathrm{B} 3176^{\mathrm{T}}$.

The hydrolytic system of $B$. fibrisolvens is however still unexplored and far less investigated than that of B. proteoclasticus. Therefore in this study, we proposed to construct a theoretical secretome of B. fibrisolvens 3071 and to compare proteomic profiles of $B$. fibrisolvens 3071 grown on four substrates, complex polysaccharide (xylan), simple pentose (xylose), simple hexose (glucose) and carbohydrate mixture (xylan+glucose), which resulted in six pair-wise comparisons.

\section{Material and methods}

\section{Bacterial strain, culture conditions and sample preparation}

Butyrivibrio fibrisolvens strain DSMZ 3071 (B. fibrisolvens 3071) was obtained from the DSMZ culture collection. B. fibrisolvens 3071 was cultivated to the late stationary phase under anaerobic conditions at $37^{\circ} \mathrm{C}$ in medium M10 [26] without rumen fluid. Various substrates including 4\% (w/v) D-xylose (Sigma-Aldrich), 4\% $(\mathrm{w} / \mathrm{v})$, D-glucose (Sigma-Aldrich), 4\% (w/v) beechwood xylan (Fluka), and the combination of $3 \%(\mathrm{w} / \mathrm{v})$ beechwood xylan (Fluka) with $1 \%(\mathrm{w} / \mathrm{v}) \mathrm{D}$-glucose (Sigma-Aldrich) were used as carbon sources. Bacteria were collected by centrifugation at $10000 \mathrm{~g}$ for $20 \mathrm{~min}$ at $4{ }^{\circ} \mathrm{C}$. The supernatants containing extracellular enzymes were further processed at $10{ }^{\circ} \mathrm{C}$ in a stirred ultrafiltration cell (Millipore) using a Millipore PES membrane with a 10 $\mathrm{kDa}$ cut off and stored immediately at $-24^{\circ} \mathrm{C}$. The 6 -fold concentrated extracellular enzyme extracts were used for monitoring the proteins secreted in response to the different growth substrates.

\section{Isolation of DNA and genome sequencing}

Genomic DNA was isolated from the B. fibrisolvens 3071 strain cultivated on DSMZ medium 330 (http:// www.dsmz.de/microorganisms/medium/pdf/DSMZ_ Medium330.pdf) under anaerobic conditions [27]. DNeasy UltraClean Microbial kit (Qiagen) was used for nucleic acid isolation with a modified lysis step with prolonged incubation at $70^{\circ} \mathrm{C}$. Genomic DNA concentration was determined using a Qubit 2.0 Fluorometer (Thermo Fisher Scientific) and the quality and integrity of DNA were checked by electrophoresis on $0.8 \%$ agarose gel. The genome was sequenced, trimmed and assembled with PacBio technology by GATC Biotech (Germany). The contigs of draft genome were processed with Geneious 9.1.8 software (Biomatters Ltd., New Zealand). The processing of output contigs was performed 
with KEGG's internal annotation tools [28] and PROKKA software tool [29].

\section{Enzyme assay}

Spectrophotometric determination of xylanase enzyme activity was performed according to Lever [30]. The assay mixture contained $100 \mu \mathrm{l}$ of culture supernatant, $100 \mathrm{mmol} / \mathrm{l}$ phosphate buffer (pH 6) and $0.5 \%(\mathrm{w} / \mathrm{v})$ carboxymethyl $(\mathrm{CM})$ xylan as a substrate [31] and was incubated for $60 \mathrm{~min}$ at $40{ }^{\circ} \mathrm{C}$. The reaction was stopped by $0.3 \mathrm{M} \mathrm{Ba}(\mathrm{OH})_{2}$ and $0.3 \mathrm{M} \mathrm{ZnSO}_{4}$, and mixture was centrifuged (6000x g,10 min). The PAHBAH reagent was added $(0.9 \mathrm{ml})$ and the mixture was boiled for $10 \mathrm{~min}$. After cooling the reducing sugars were measured spectrophotometrically at $410 \mathrm{~nm}$ (Biomate 5 , UK).

The activity of $\beta$-xylosidase was determined according to Bidochka [32]. The assay mixture contained $100 \mu \mathrm{l}$ of culture supernatant, $100 \mathrm{mmol} / \mathrm{l}$ phosphate buffer $(\mathrm{pH} 6)$ and $0.5 \% \quad(\mathrm{w} / \mathrm{v}) \quad \mathrm{p}$-nitrophenyl- $\beta$-D-xylopyranoside $(p$-NPX) (P-LAB) as the substrate and was incubated for $60 \mathrm{~min}$ at $40{ }^{\circ} \mathrm{C}$. The reaction was stopped by $0.8 \mathrm{ml} 2 \%$ (w/v) $\mathrm{Na}_{2} \mathrm{CO}_{3}$ and mixture was centrifuged (6000x g, 10 $\mathrm{min})$. The reducing sugars were measured spectrophotometrically at $410 \mathrm{~nm}$ (Biomate 5, UK).

The protein concentration was determined according to Bradford [33]. Bovine serum albumin (BSA) solution (Sigma-Aldrich) was used for calibration. Two hundred $\mu \mathrm{l}$ of working solution (Coomassie Brilliant Blue G-250) (Bio-Rad) and $4 \mu \mathrm{l}$ sample (or standard) were pipetted into the 96 well microplate. The absorbance was measured at $595 \mathrm{~nm}$ (Sunrise, Tecan, Scholler) and the concentration of proteins in the sample was calculated using the linear regression method.

\section{Sodium dodecyl sulphate-polyacrylamide gel electrophoresis (SDS-PAGE) and zymography} SDS-PAGE of crude extracellular extracts of B. fibrisolvens 3071 grown in medium with different substrates as described above was performed according to Laemmli [34] on a slab of $8 \%$ polyacrylamide gel in a Mini-Protean Tetra cell system (Bio-Rad) at $110 \mathrm{~V}$ for $1.5 \mathrm{~h}$. Protein bands were visualized with Bio-Safe Coomassie R-250 Staining Solution (Bio-Rad) and analysed in a GS-700 Imaging Densitometer (Bio-Rad). Zymograms were prepared according to Flint et al. [35] using 0,1\% (w/v) carboxy-methyl (CM) xylan as the substrate [31] on a slab of $8 \%$ polyacrylamide gel under the same conditions as for SDS-PAGE. The gel was washed with $1 \%(\mathrm{v} / \mathrm{w})$ Triton X100 (Fluka) for $30 \mathrm{~min}$ and three times with $25 \mathrm{mM}$ phosphate buffer $(\mathrm{pH} 7,5)$ to allow the renaturation of enzymes. The gel was then incubated for $20 \mathrm{~min}$ at $39^{\circ} \mathrm{C}$ in $25 \mathrm{mM}$ phosphate buffer $(\mathrm{pH} 7,5)$ and stained in $0.1 \%(\mathrm{v} / \mathrm{w})$ Congo Red (Sigma-Aldrich) for 30 min. The highlighted spots indicated xylanase activity against a red background after destaining with $1 \mathrm{M} \mathrm{NaCl}$.

\section{Two dimensional gel electrophoresis}

The comparison of four different carbon sources was based on pair-wise matching with two replicates for each substrate (8 gels) (Additional file 2: Table S2, Figures S1-S12). Protein samples were precipitated for $1 \mathrm{~h}$ using $10 \%$ trichloroacetic acid $(\mathrm{w} / \mathrm{v})$ and pelleted by centrifugation at $4^{\circ} \mathrm{C}, 7500 \mathrm{x} \mathrm{g}$ for $15 \mathrm{~min}$. Pellets were washed with $1 \mathrm{ml}$ of ice-cold acetonitrile, incubated with acetonitrile at $4{ }^{\circ} \mathrm{C}$ for $1 \mathrm{~h}$, and centrifuged at $4{ }^{\circ} \mathrm{C}, 7500 \mathrm{xg}$ for $15 \mathrm{~min}$. The washing step was repeated with acetone and acetonitrile, and the pellets were dried for $1 \mathrm{~h}$ at room temperature. Samples were resuspended in lysis buffer $(7 \mathrm{M}$ urea, $4 \mathrm{M}$ thiourea, $4 \%(\mathrm{w} / \mathrm{v})$ CHAPS, $0.6 \%(\mathrm{w} / \mathrm{v})$ Biolyt and $1 \%(\mathrm{w} / \mathrm{v})$ DTT) to achieve a final protein concentration of $1 \mathrm{mg} / \mathrm{ml}$. One hundred and forty $\mu$ of sample was applied to a 7-cm IPG strip with a linear gradient of pH 4-7 (ReadyStripTM IPG Strips, Bio-Rad). Isoelectric focusing (IEF) was carried out on IPG strips using a Protean IEF cell system (Bio-Rad). Before the second dimension step, focused strips were equilibrated for $10 \mathrm{~min}$ in $1 \mathrm{ml}$ of equilibration solution $(0,375 \mathrm{mM}$ Tris/ $\mathrm{HCl}, \mathrm{pH} 8.8,6 \mathrm{M}$ urea, 20\% (v/v) glycerol, 2\% (w/v) SDS, 0,005\% BPB (bromophenol blue) and 2\% (w/v) DTT (dithiothreitol), and then in the same buffer solution supplemented with $4 \%(w / v)$ IA (iodoacetamide) instead of DTT. The strips were then rinsed in Tris-glycine buffer ( $\mathrm{pH}$ 8.5) and the second dimension was performed in a homogeneous $10 \%$ SDS-PAGE gel at $110 \mathrm{~V}$ for $1.5 \mathrm{~h}$ using a Mini-Protean Tetra cell system (Bio-Rad). The gels were fixed and stained with Bio-Safe Coomassie R-250 Staining Solution (Bio-Rad) and scanned using a GS- $800^{\text {max }}$ Calibrated Imaging Densitometer (Bio-Rad). The protein spots were detected and their intensities quantified using PDQuest TM software (version 8.0.1. Bio-Rad). For statistical analysis, the two-tailed Student t-test $(p<0.05)$ was used to assess the statistical significance of changes in protein abundance.

\section{Mass spectrometry and bioinformatics}

Spots indicating significant differences between the used substrates $(\mathrm{p}<0.05)$ were excised from the gels and processed according to Schevchenko et al. [36]. The excised spots were digested in solution containing $\mathrm{NH}_{4} \mathrm{HCO}_{3}(0.05$ $\mathrm{mol} / \mathrm{l})$ and trypsin $(0.02 \mathrm{mg} / \mathrm{ml})$ at $37^{\circ} \mathrm{C}$ for $16 \mathrm{~h}$. Extracted peptides were purified using Stage Tips [37]. Extracted solutions were lyophilized and dissolved in $20 \mu \mathrm{l}$ of $2 \%$ formic acid (v/v) for consequent nLC MS/MS analysis. Protein digests were analysed by a nano-liquid chromatography in a Proxeon Easy-nLC (Proxeon, Odense, Denmark) coupled to a MaXis quadrupole time-of-flight (Q-TOF) mass spectrometer (Bruker Daltonics, Bremen, Germany) according to Oštádal et al. [38]. The samples of the peptide mixture were injected into an NS-AC-11-C18 Biosphere column (particle size $5 \mu \mathrm{m}$, length $150 \mathrm{~mm}$, pore size: $12 \mathrm{~nm}$, inner diameter $75 \mu \mathrm{m}$ ) with an NS-MP-10 Biosphere C18 
precolumn (particle size $5 \mu \mathrm{m}$, length $20 \mathrm{~mm}$, pore size: 12 $\mathrm{nm}$, inner diameter $100 \mu \mathrm{m})$ (NanoSeparations, Netherlands).

Data were processed with the software ProteinScape v. 3.0.0.446 (Bruker Daltonics, Bremen, Germany). Proteins were identified by correlating tandem mass spectra to the extracted database for Butyrivibrio fibrisolvens from the NCBI database (downloaded on 26th February 2018; 33,312 proteins), using the MASCOT search engine $\mathrm{v}$. 2.3.0 (http://www.matrixscience.com).

Trypsin was selected as the enzyme parameter. One missed cleavage was allowed, an initial peptide mass tolerance of $\pm 10.0 \mathrm{ppm}$ was used for MS and $0.05 \mathrm{Da}$ for MS/ MS analysis. Cysteines were assumed to be carbamidomethylated, proline and lysine to be hydroxylated, serine, threonine and tyrosine to be phosphorylated and methionine was allowed to be oxidized. All of these possible modifications were set to be variable. Monoisotopic peptide charge was set to $1+, 2+$, and $3+$. The Peptide Decoy option was selected during the data search process to remove false-positive results. The hits (MASCOT score $\geq$ 80, www.matrixscience.com) were accepted as significant. The metabolic pathways involving the observed enzymes were found using the website www.kegg.jp.

The isoelectric point of the proteins was estimated using the EMBOSS iep online tool (http://emboss.bioinformatics.nl/cgi-bin/emboss/iep). The molecular weight of the proteins was calculated using the online tool Protein Molecular Weight (http://www.bioinformatics.org/sms2/protein_mw.html). The carbohydrate metabolism proteins were identified using the Blast Koala online tool [28].

\section{Results}

\section{Genome sequencing, theoretical proteome and enzyme assay}

The genome of B. fibrisolvens 3071 encodes 4079 coding sequences. According to the KEGG annotation, the major group of genes belonged to the Environmental Information Processing group (13.7\%), followed by Carbohydrate metabolism genes (12.8\%) and genes of Protein families for genetic information processing (12.5\%), Protein families for signalling and cellular processes (11.1\%) and Genetic Information Processing (11.3\%). The Carbohydrate metabolism group includes 99 distinct Glycoside Hydrolase (GHs), 8 Carbohydrate Esterase (CEs) and 48 Glycoside Transferase (GTs) genes (Fig. 1a). Resulting annotated genome files (Additional file 1: Table S1) are in the Supplementary data.

The theoretical 2DE map constructed on the basis of the sequencing data indicates that the proteome of $B$. fibrisolvens 3071 consists of 4035 proteins. There were 2941 proteins $(73 \%)$ possessing a theoretical $\mathrm{p} I<7$, the majority of them ranging between $\mathrm{pI} 4$ and 7, other 1095 proteins $(27 \%)$ had theoretical $\mathrm{p} I>7$ and only 172 proteins $(4 \%)$ had pI $>10$. Ninety-three percent of the predicted proteins (3754) had predicted polypeptide masses between 10 and $150 \mathrm{kDa}$ (Fig. 1b).

Seven genes of endo- $\beta$-1,4-xylanase (EC 3.2.1.8) and 8 genes of xylan 1,4- $\beta$-xylosidase (EC 3.2.1.37) were detected in the genome. To verify the extracellular xylanolytic potential of strain 3071, the activities of xylanase, cleaving $\beta-1,4-x y l o s i d i c$ linkages randomly within the xylan chain, and the activities of xylosidase, which removes successive xylose residues from the non-reducing termini, were investigated in the culture medium of B. fibrisolvens 3071 grown on four different substrates. Figure 2 shows that the production of both enzymes is dependent on the nature of the carbon source. Both enzymes were induced by the presence of xylan, especially xylanase, while xylosidase was also induced by monomeric xylose.

\section{SDS PAGE, 2-D electrophoresis and protein characterization}

SDS-PAGE analysis of the extracellular protein pattern of B. fibrisolvens 3071 grown on four different carbon sources revealed the major protein bands, with a higher intensity of estimated masses from 40 to $80 \mathrm{kDa}$ when grown on xylan and a combination of xylan and glucose. Several protein bands of 58 to $80 \mathrm{kDa}$ were visible for the strain cultivated on xylan and xylan+glucose, while these fragments were absent for cultivation on glucose and xylose. The zymogram shows differences in xylanase isoenzymes, in the range from 32 to $130 \mathrm{kDa}$, when $x y$ lan and xylan+glucose were used as the substrate. Only weak bands at 70 and $58 \mathrm{kDa}$ were detected on the zymogram for enzymes from the strain grown on glucose and xylose (Fig. 3).

Two-dimensional electrophoreses were carried out to identify the protein spot profiles of B. fibrisolvens 3071 grown on four different carbon sources. Substrates were compared to each other, amounting to six comparisons: (I) glucose/xylan, (II) glucose/xylan + glucose, (III) glucose/xylose, (IV) xylan/xylan + glucose, (V) xylan/xylose, (VI) xylan + glucose/xylose. Each comparison was performed in duplicate. From these eight 2-D electrophoresis gels, a total of 141 spots were excised and processed. Analysis of the nLC/ MS protein peaks revealed that only 14 proteins (28 spots) fulfilled the MASCOT Score Criteria and were found as differentially expressed depending on the used carbon source, as shown in Fig. 4 and summarized in Table 1. These groups of proteins are involved in glycolysis, protein synthesis and butyrate synthesis. The identified proteins were functionally categorized as hydrolases (2), lyases (1), isomerases (1), transferases (3), oxidoreductases (2) and 3 proteins matched with Elongation factor Ts. The functions of these proteins and their involvement in the metabolic pathway are described in Table 2. 
A

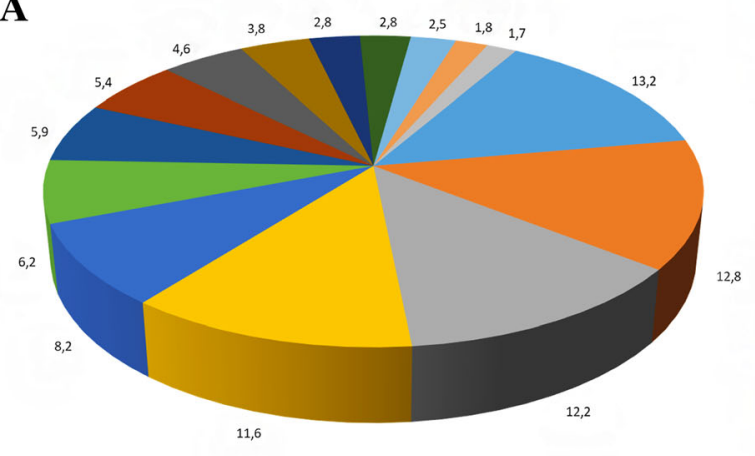

B
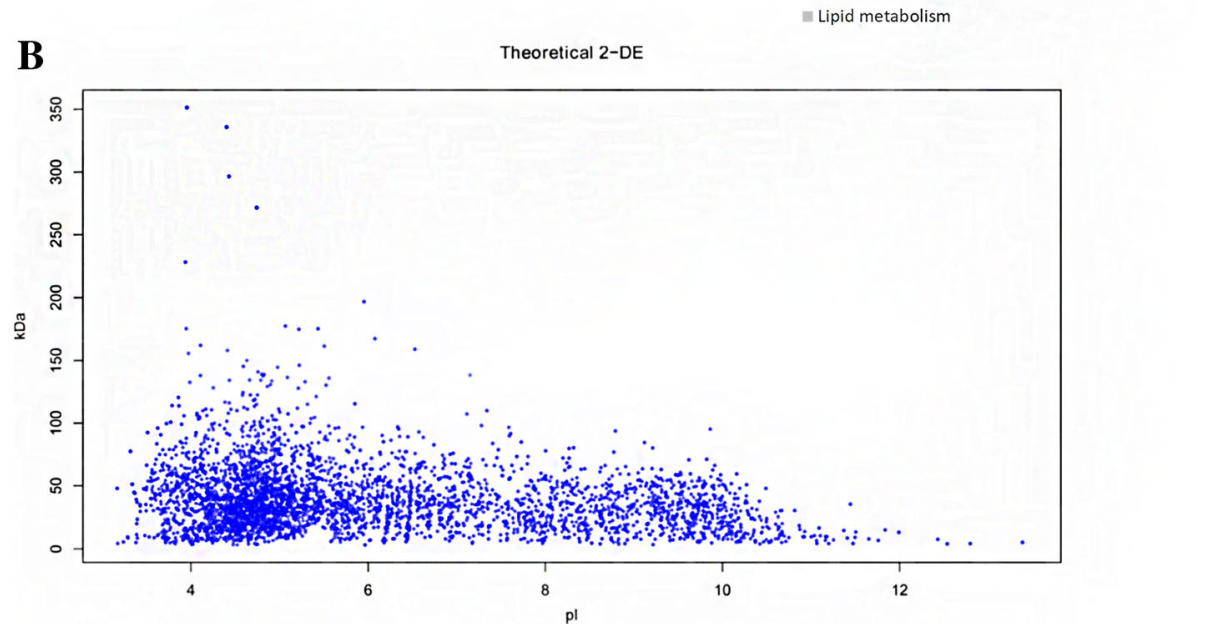

Invironmental Information Processing

n Carbohydrate metabolism

In Protein families: genetic information processing

= Protein families: signalling and cellular processes

nenetic Information Processing

- Unclassified

- Amino acid metabolism

- Unclassified: metabolism

- Nucleotide metabolism

- Metabolism of cofactors and vitamins

- Cellular Processes

- Protein families: metabolism

= Energy metabolism

In Unclassified: genetic information processing

E Lipid metabolism

Fig. 1 Protein function summary of all proteins identified in B. fibrisolvens 3071 (a) and theoretical 2DE map of total proteins (b). Blue spots represent all predicted proteins

The enzymes involved in the process of degrading structural polysaccharides in the rumen were mapped using the KEGG database and the position and role of proteins of B. fibrisolvens 3071 in metabolic pathways were identified (Fig. 5).

\section{Discussion}

Butyrivibria are considered to be an integral part of the bovine rumen bacteriome associated with the host genetic background, thus forming inheritable microbiota [2]. The biggest advantage of these bacteria is in the

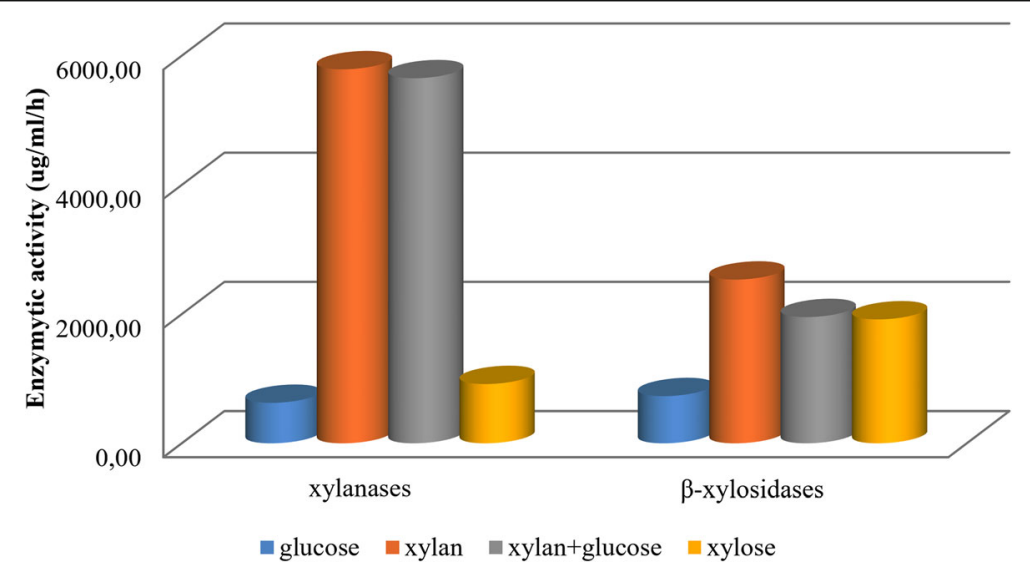

Fig. 2 The comparison of xylanase and $\beta$-xylosidase activities of $B$. fibrisolvens 3071 grown on four different carbon sources: glucose (4 g/l), xylan $(4 \mathrm{~g} / \mathrm{l})$, xylan $(3 \mathrm{~g} / \mathrm{l})+\mathrm{glucose}(1 \mathrm{~g} / \mathrm{l})$, and xylose $(4 \mathrm{~g} / \mathrm{l})$ 
A

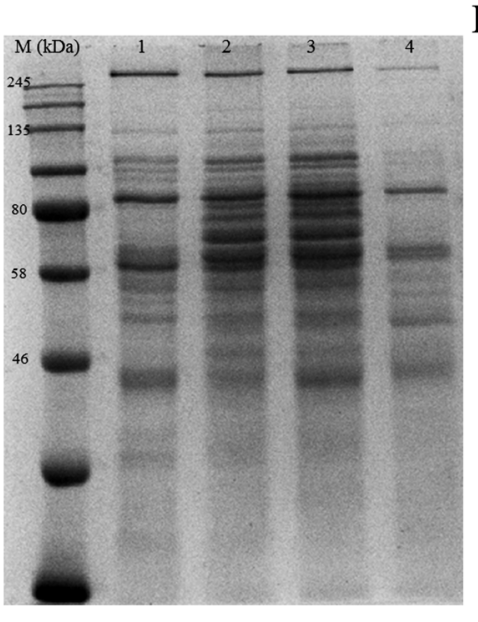

C

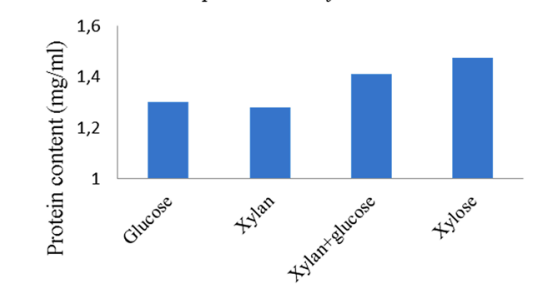

B

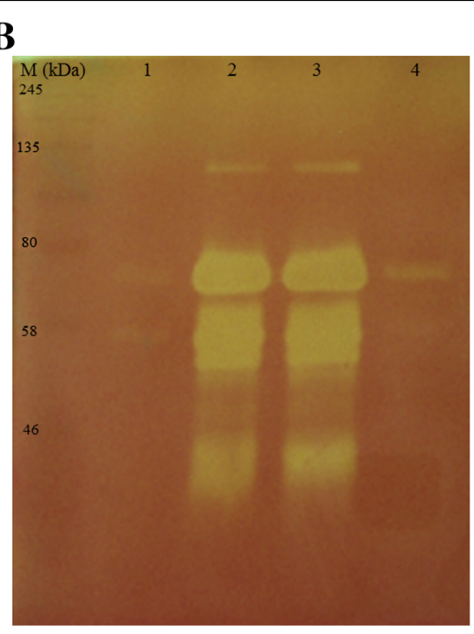

Fig. 3 SDS PAGE (a) and zymogram (b) of extracellular proteins of B. fibrisolvens 3071. Strain was grown on the following carbon sources: 1 glucose, 2 - xylan, 3-xylan and glucose, 4 - xylose. The MW protein standard was in the range $11-245 \mathrm{kDa}$. The protein concentrations in samples loaded onto both gels above is illustrated by blue columns (c)

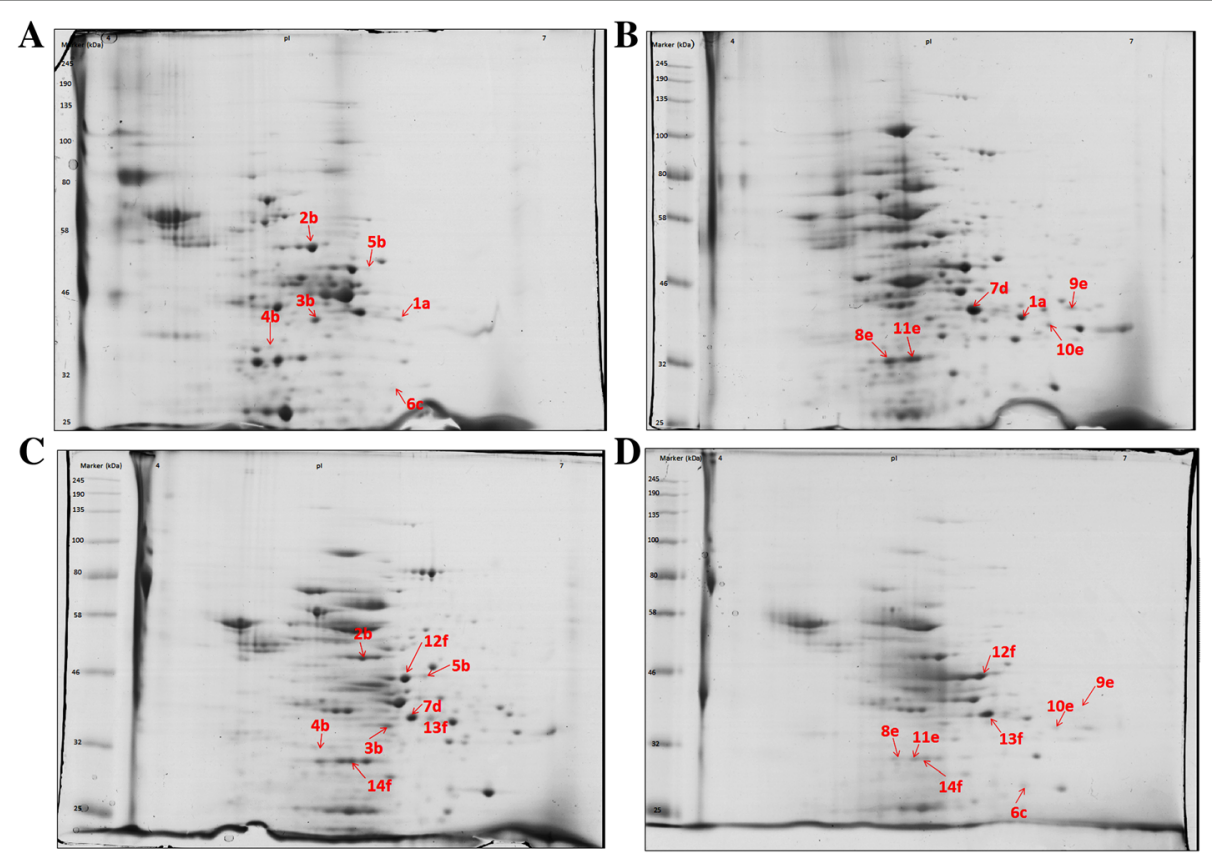

Fig. 4 Two-dimensional gel electrophoresis of extracellular proteins of B. fibrisolvens 3071 grown on different substrates. The gels $(\mathbf{a}, \mathbf{b}, \mathbf{c}$, $\mathbf{d})$ show spots from cultivation on glucose, xylan, xylan + glucose, and xylose, respectively. The letters a, b, c, d, e, f indicate the identical spots, however with significantly different intensity, in the comparison of B. fibrisolvens 3071 grown on glucose/xylan, glucose/xylan + glucose, glucose/xylan + glucose, xylan/xylan+glucose, xylan/xylose, xylan+glucose/xylose, respectively. Annotations correspond to spot numbers in Table 1. The MW protein standard was in the range $11-245 \mathrm{kDa}$ 
Table 1 List of B. fibrisolvens 3071 proteins identified and confirmed by nLC/MS as significantly different. The spots were excised from the 2-D electrophoresis gels comparing glucose/xylan (I), glucose/xylan + glucose (II), glucose/xylose (III), xylan/xylan + glucose (IV), xylan/xylose (V), xylan + glucose/xylose (VI)

\begin{tabular}{|c|c|c|c|c|c|c|c|}
\hline $\begin{array}{l}\text { Substrate } \\
\text { comparison }\end{array}$ & $\begin{array}{l}\text { Spot } \\
\text { number }\end{array}$ & $\begin{array}{l}\text { Accession } \\
\text { number }\end{array}$ & Protein & $\begin{array}{l}\text { Total number } \\
\text { of peptides }\end{array}$ & $\begin{array}{l}\text { Fold } \\
\text { change }\end{array}$ & MW & $\mathrm{pl}$ \\
\hline I & $1 \mathrm{a}$ & SHI27642.1 & diaminopimelate dehydrogenase & 3 & $3.99 \uparrow g^{1}$ & 36.2 & 5.5 \\
\hline \multirow[t]{4}{*}{ ॥ } & $2 b$ & SHH89614.1 & glucose-6-phosphate isomerase & 18 & $0.61 \uparrow x+g^{3}$ & 56.9 & 5.1 \\
\hline & $3 b$ & SHI23166.1 & $\mathrm{N}$-acetylmuramoyl-L-alanine amidase & 6 & $0.44 \uparrow x+g^{3}$ & 38.9 & 5.2 \\
\hline & $4 b$ & SHH52657.1 & 1-phosphofructokinase & 9 & $0.61 \uparrow x+g^{3}$ & 32.6 & 4.7 \\
\hline & $5 b$ & SER24636.1 & phosphoglycerate kinase & 6 & $2.02 \uparrow g^{1}$ & 43.8 & 5.2 \\
\hline III & $6 c$ & BAD51424.1 & beta-hydroxybutyryl-CoA dehydrogenase & 7 & $2.29 \uparrow g^{1}$ & 31.5 & 5.7 \\
\hline IV & $7 d$ & SHI29611.1 & fructose-bisphosphate aldolase, class II & 19 & $0.61 \uparrow x+g^{3}$ & 33.9 & 5.2 \\
\hline \multirow[t]{4}{*}{ V } & $8 e$ & SHI15246.1 & elongation factor Ts & 13 & $\left.0.81 \uparrow x y\right|^{4}$ & 34.6 & 4.8 \\
\hline & $9 e$ & SHI83999.1 & glyceraldehyde 3-phosphate dehydrogenase & 8 & $\left.0.88 \uparrow x y\right|^{4}$ & 36.9 & 5.8 \\
\hline & $10 e$ & SHH82532.1 & 3-deoxy-D-arabinoheptulosonate-7-phosphate synthase & 2 & $0.69 \uparrow x^{2}$ & 38.5 & 6.0 \\
\hline & $11 e$ & SHI15246.1 & elongation factor Ts & 13 & $0.93 \uparrow x^{2}$ & 34.6 & 4.8 \\
\hline \multirow[t]{3}{*}{$\mathrm{Vl}$} & $12 f$ & SER24636.1 & phosphoglycerate kinase & 2 & $2.22 \uparrow x+g^{3}$ & 46.8 & 5.2 \\
\hline & $13 f$ & SER75936.1 & fructose-bisphosphate aldolase, class II & 7 & $1.04 \uparrow x+g^{3}$ & 33.9 & 5.2 \\
\hline & $14 f$ & SHI15246.1 & elongation factor Ts & 2 & $\left.0.62 \uparrow x y\right|^{4}$ & 34.6 & 4.8 \\
\hline
\end{tabular}

Superscript 1, 2, 3, and 4 indicate glucose, xylan, xylan and glucose, and xylose, respectively

relatively broad spectrum of utilizable substrates and especially important is their xylanolytic activity [12]. The substrate flexibility of butyrivibria species was clearly documented by a study of the B. proteoclasticus glycobiome which covered a wide range of degrading and transporting proteins for different structural and storage polysaccharides [23], as well as a wide spectrum of oligosaccharides [24]. Due to the mobility of Butyrivibria, mediated by flagella, these strains also represent the most rapid colonizers of solid substrates in the rumen [4].

The sizes of genomes of $B$. fibrisolvens species sequenced to date range from 4462 up to $5121 \mathrm{~kb}$. This corresponds well with our results, and shows that $B$. fibrisolvens as well as B. proteoclasticus [22, 49] have bigger genomes than other Butyrivibria and Pseudobutyrivibria. Their genomes have been determined in the range from 2100 to $4404 \mathrm{~kb}$. In the $B$. fibrisolvens 3071 genome ten different endo-1,4- $\beta$-xylanase genes or precursors, and eight 1,4- $\beta$-xylosidase genes have been identified. The enzyme activity measurement and zymogram analysis confirmed that xylanase isoenzymes were in the extracellular fraction and were induced by xylan, even in the presence of a minor amount of glucose. These results are in agreement with the studies [50-53], however Sewell et al. [11] observed that xylosidase activity was mainly cell-associated and cellular xylanase activity rapidly declined in the presence of a small amount of glucose.

This study however mainly aimed to examine changes in the extracellular protein expression of $B$. fibrisolvens 3071 when this xylanolytic organism was grown on a variety of bioenergy-relevant substrates in order to identify the proteins responsible for substrate-specific breakdown and/or utilization. The substrates chosen ranged from simple (monomeric) to complex (polymeric), and varied in their general composition ( $\mathrm{C} 5$ or C6 sugars). Proteomic analysis resulted in the highest number of spots when xylan was used as a substrate. Nearly all proteins were located in the central pI region. Comparison of proteome derived from simple sugars (glucose, xylose) exhibited a higher fold change in the proteins in the strain cultured on glucose, which indicates a tendency for a preferred sugar, which in the rumen is generally glucose, released by the hydrolysis of polysaccharides [18]. Xylose is not as efficiently utilized as glucose, which is caused by the different metabolic pathways of pentose and hexoses [54]. Pentose sugar represents about one-third of the total carbohydrate monomers in lignocellulosic biomass, which is a mixture of carbohydrate polymers (mainly cellulose and hemicellulose) and lignin [55]. The model of hemicellulose degradation by Butyrivibria was suggested by Palevich et al. [56] showing that the unsubstituted xylan chain is mainly degraded to xylose, which is transferred into the bacterial cell via xylose $A B C$ transporters. Substituted xylo-oligosaccharides are transported by other $A B C$ transporters and degraded by specific glycosidases in the cell cytoplasm.

In contrast to the results of Dunne et al. [24], who described debranching arabinofuranosidases, esterases, endo- $\beta-1,4$-xylanase and $\beta$-xylosidase enzymes in intracellular proteome Butyrivibrio proteoclasticus cultures, we did not identify the xylanolytic enzymes as significantly 


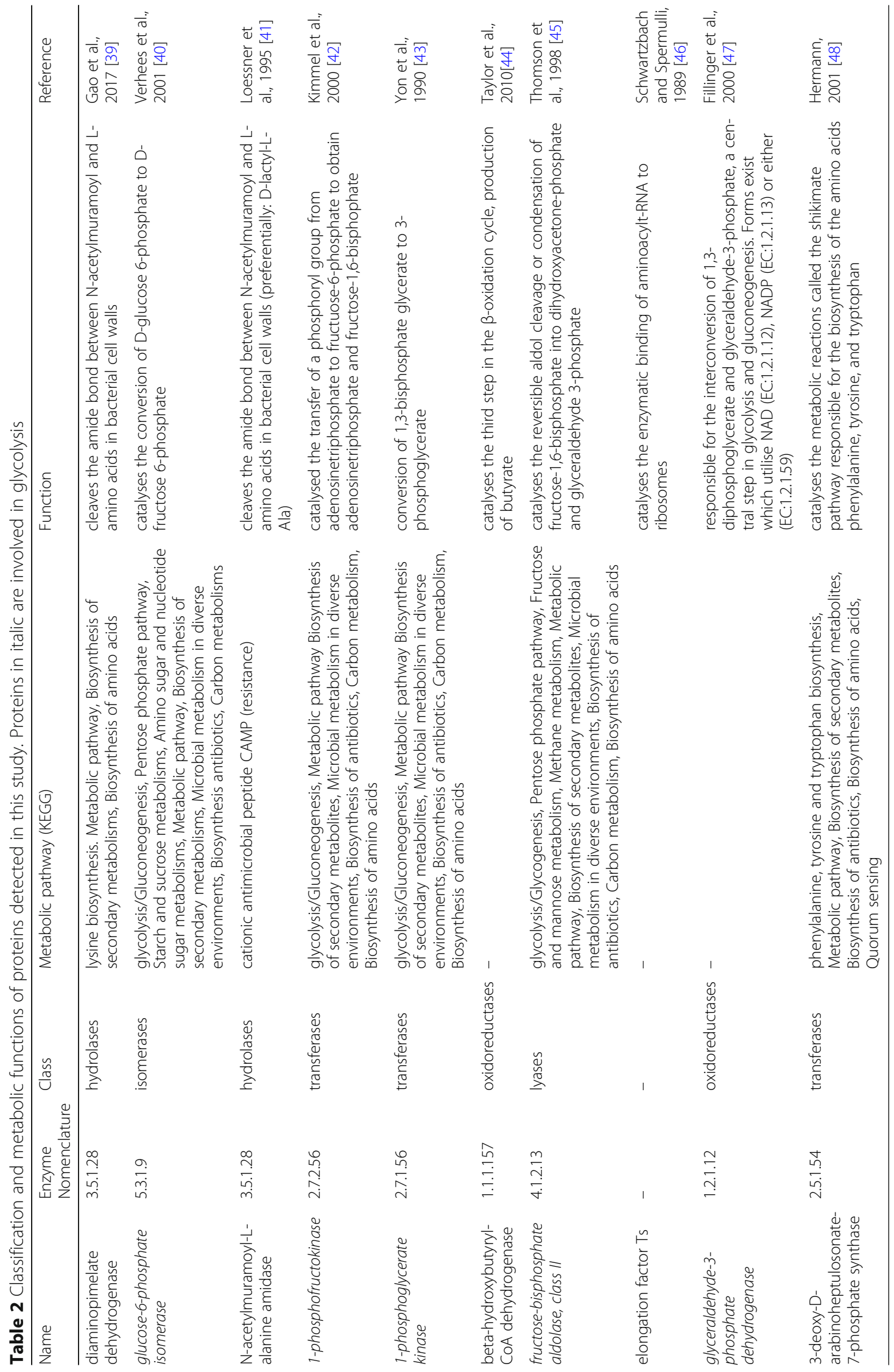




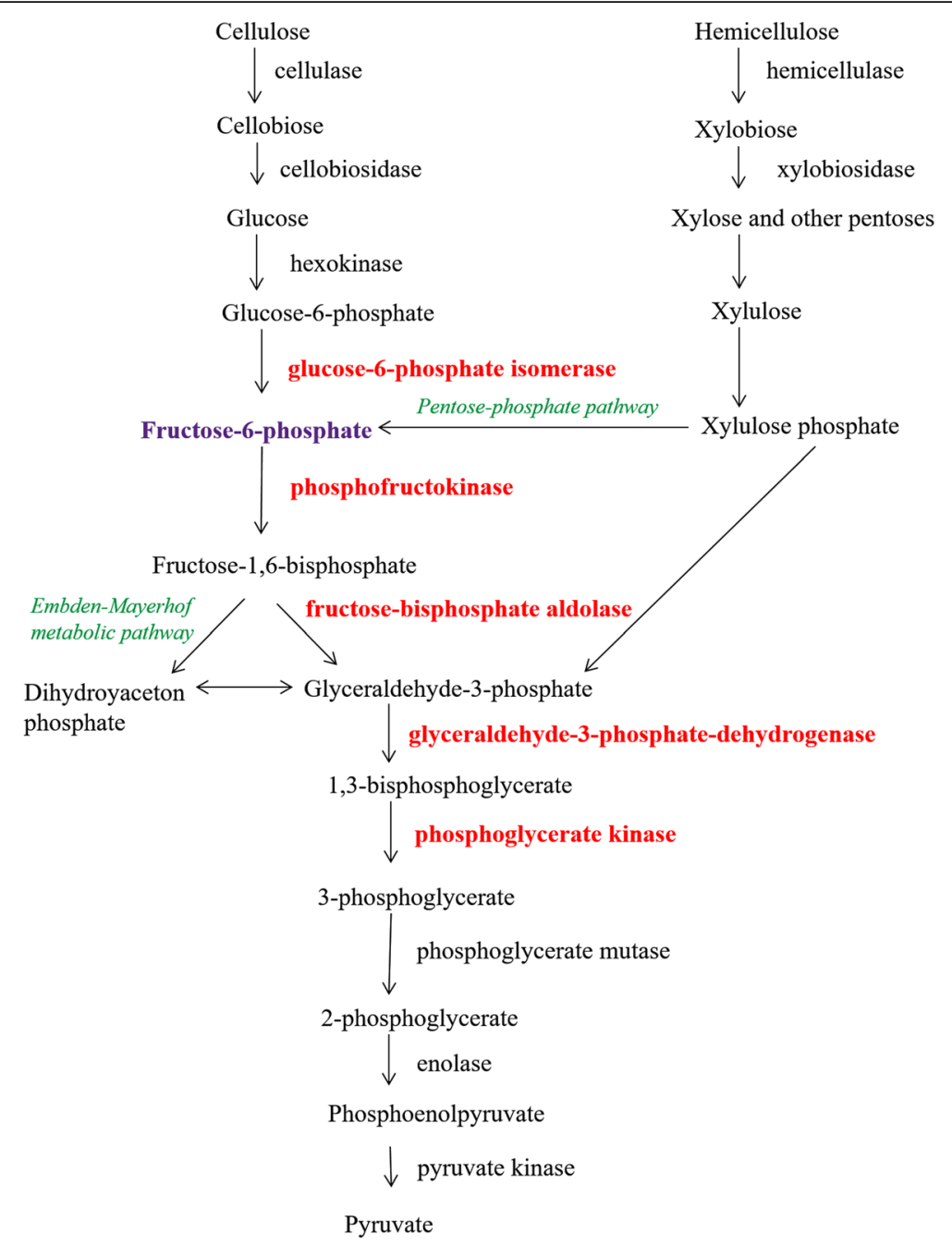

Fig. 5 Scheme of metabolic pathway of decomposition of plant carbohydrates by B. fibrisolvens 3071. Red colour indicates enzymes detected in this study as spots with significantly different intensity depending on the carbon source

different with the carbon source used in this study. However, the design of our experiment was differed from study of Dunne et al. [24]. We did not study the whole proteome, but we aimed to compare the proteins which were differentially produced by $B$. fibrisolvens 3071 cultivated on different carbon sources.

In our work a significant regulation was observed in the extracellular fraction of groups of proteins involved in glycolysis and protein synthesis. The proteins affected in our analysis are the same as identified by Snelling and Wallace [21], who explored the ruminal digesta proteome of cattle, sheep and reindeer. These authors identified the glyceraldehyde-3-phosphate dehydrogenase, phosphoenolpyruvate carboxykinase, phosphoglycerate kinase and triosephosphate isomerase as a dominant enzymes of ruminal bacterial proteome. Two of these enzymes were also detected in our work as differentially expressed depending on carbon source. We also detected enzymes fructose- 1,6-bisphosphate aldolase, glucose-6-phosphate isomerase involved in glycolysis. Snelling and Wallace [21] detected the beta-hydroxybutyryl-CoA dehydrogenase of B. fibrisolvens as the abundant prokaryotic protein in the rumen. These results support the high importance of $B$. fibrisolvens in the rumen ecosystem in spite of its low number [57]. The proteins involved in glycolysis, protein synthesis and carbohydrate metabolism were identified as the predominant pathways also by Hart et al. [58], who moreover also described the protein family containing the elongation factor $\mathrm{Tu}$ as being the most highly abundant in the bovine rumen ecosystem. Upregulated proteins of central carbon catabolic pathways have also been described by Ruminiclostridium cellulolyticum cultivated on different sources of fibre [59]. We find very interesting that proteomic studies performed on rumen fluid of different animals [21,58] brought the same results as our work studying one pure bacterial strain. In our opinion this can indicate that the proteins of 
glycolysis, which provides sources energy to host animal, play a very crucial role and are essential for the metabolism of ruminants.

\section{Conclusion}

This study was focused on the effect of substrates (glucose, xylan, xylan and glucose and xylose) on the expression of extracellular proteins. In B. fibrisolvens 3071 cultures, both extracellular $\beta$-endoxylanase activity and xylan $\beta$-xylosidase were induced by xylan. Xylan induced several hemicellulolytic isoenzymes in the interval from 32 to $130 \mathrm{kDa}$.

Proteomic analysis comparing complex and simple carbon sources revealed only limited numbers of significantly differently expressed proteins. These proteins are involved in glycolysis, protein synthesis and butyrate synthesis. Such a result was unexpected but not exceptional. Higher levels of the enzymes from the central carbon catabolic pathways were obtained in a bacterial monoculture of Ruminiclostridium cellulolyticum [59], as well as in the whole rumen microbial community [21, 58]. This is the first proteomic study of B. fibrisolvens 3071 indicating that this strain can play the important role for the central rumen catabolic metabolism.

\section{Additional files}

Additional file 1: Table S1. Genome of Butyrivibrio fibrisolvens 3071 sequenced by PacBio annotated with Blast Koala (KEGG). (DOCX 15 kb)

Additional file 2: Table S2. Results of statistic evaluation (Student's test) and six pair-wise comparisons of $2 \mathrm{D}$ gels separating proteins of $\mathrm{B}$. fibrisolvens 3071 grown on four different substrates (I - glucose, II - xylan, III xylan+glucose, 4 - xylose). Figure S1. 2D gel separation of proteins of B.fibrisolvens 3071 cultivated on glucose (I). Figure S2. 2D gel separation of proteins of B.fibrisolvens 3071 cultivated on xylan (II). Figure S3. 2D gel separation of proteins of B.fibrisolvens 3071 cultivated on glucose (I). Figure S4. 2D gel separation of proteins of B.fibrisolvens 3071 cultivation on xylan+glucose (III). Figure S5. 2D gel separation of proteins of B.fibrisolvens 3071 cultivated on glucose (I). Figure S6. 2D gel separation of proteins of B.fibrisolvens 3071 cultivated on xylose (IV). Figure S7. 2D gel separation of proteins of B.fibrisolvens 3071 cultivated on xylan (II). Figure S8. 2D gel separation of proteins of B.fibrisolvens 3071 on xylan+glucose (III). Figure S9. 2D gel separation of proteins of B.fibrisolvens 3071 cultivated on xylan (II). Figure S10. 2D gel separation of proteins of B.fibrisolvens 3071 cultivate on xylose (IV). Figure S11. 2D gel separation of proteins of B.fibrisolvens 3071 cultivated on xylan+glucose (III). Figure S12. 2D gel separation of proteins of B.fibrisolvens 3071 cultivated on xylose (IV). (DOCX $2222 \mathrm{~kb})$

\footnotetext{
Abbreviations

2D: Two Dimensional; 2DE: Two dimensional Electrophoresis; BPB: Bromophenol Blue; BSA: Bovine Serum Albumin; C5 sugar: Five Carbon Sugar; C6 sugar: Six Carbon Sugar; CCR: Carbon Catabolic Repression; CE: Carbohydrate Esterase; CHAPS: 3-[(3-cholamidopropyl) dimethylammonio]-1-propanesulfonate; CM: Carboxymethyl; DSMZ: Deutsche Sammlung von Mikroorganismen und Zellkuturen; DTT: Dithiothreitol; EC Number: Enzyme Commission Number; GH: Glycoside Hydrolase; GT: Glycoside Transferase; IA: lodoacetamide; IEF: Isoelectric Focusing; IPG: Immobilized pH gradient; MS: Mass Spectrometry; MS/MS: Tandem Mass Spectrometry; MW: Molecular weight; nLC: Nano Liquid Chromatography; PAHBAH: 4-hydroxybenzoic acid hydrazide; PES: Polyethersulfone; $p$-NPX: p-
}

Nitrophenyl- $\beta$-D-xylopyranoside; SDS-PAGE: Sodium Dodecyl SulphatePolyacrylamide Gel Electrophoresis; TGPA: Thermophilic Gram Positive Anaerobes; UK: United Kingdom

\section{Acknowledgements}

The authors acknowledge Ing. Statis Pataridis and Adam Eckhardt, Ph.D. (Institute of Physiology, CAS, v.v.i) for their help and assistance with nLC/MS.

\section{Funding}

The authors would like to acknowledge funding support from the Czech Science Foundation (16-12431S) and the EU FP7 project RUMINOMICS (No. 289319).

The study was supported by Charles University in Prague, project GA UK No. 322216. This research was carried out within the framework of Specific University Research (SW260440).

This study was supported by Project Excellence (No. CZ.02.1.01/0.0/0.0/ 15_003/0000460).

We gratefully acknowledge the support of this work by institutional support RVO 86652036.

\section{Availability of data and materials}

We are ready to share our data.

\section{Authors' contributions}

HS experiment setup, data interpretation, manuscript writing; JK evaluation of enzyme activities, genome sequencing and manuscript writing; KF major contributor in writing the manuscript; LK participated in 2-D electrophoresis and proteomic techniques; MT proteomic consulting; DM bioinformatics analysis; JM genomics and sequencing. All authors read and approved the final manuscript.

\section{Ethics approval and consent to participate}

B. fibrisolvens 3071 was provided by the Collection of Microorganisms of the Institute of Animal Physiology and Genetics CAS, Prague, Czech Republic.

\section{Consent for publication}

Not applicable.

\section{Competing interests}

The authors declare that they have no competing interests.

\section{Publisher's Note}

Springer Nature remains neutral with regard to jurisdictional claims in published maps and institutional affiliations.

\section{Author details}

${ }^{1}$ Institute of Animal Physiology and Genetics, CAS, v.v.i., Vídeňská 1083, 142 20 Prague, Czech Republic. ${ }^{2}$ Institute of Physiology, CAS, v.v.i., Vídeňská 1083, 14220 Prague, Czech Republic. Institute of Biotechnology, CAS, v.vi.i, Průmyslová 595, 25250 Vestec, Czech Republic. ${ }^{4}$ Department of Analytical Chemistry, Faculty of Science, Charles University in Prague, Hlavova 8, 12843 Prague 2, Czech Republic. ${ }^{5}$ Department of Biochemistry and Microbiology, Faculty of Food and Biochemical Technology, University of Chemistry and Technology, Technická 5, 166286 Prague, Czech Republic. ${ }^{6}$ Institute of Microbiology, CAS, v.vi., Vídeňská 1083, 14220 Prague, Czech Republic.

Received: 21 November 2018 Accepted: 15 May 2019 Published online: 01 June 2019

\section{References}

1. Bryant MP, Small N. The anaerobic monotrichous butyric acid-producing curved rod-shaped bacteria of the rumen. J Bacteriol. 1956;72(1):16-21.

2. Gonzalez-Recio O, Zubiria I, Garcia-Rodriguez A, Hurtado A, Atxaerandio R. Short communication: signs of host genetic regulation in the microbiome composition in 2 dairy breeds: Holstein and Brown Swiss. J Dairy Sci. 2018; 101(3):2285-92.

3. Derakhshani H, Tun HM, Cardoso FC, Plaizier JC, Khafipour E, Loor JJ. Linking Peripartal dynamics of ruminal microbiota to dietary changes and production parameters. Front Microbiol. 2016;7:2143.

4. Mayorga OL, Kingston-Smith AH, Kim EJ, Allison GG, Wilkinson TJ, Hegarty MJ, Theodorou MK, Newbold CJ, Huws SA. Temporal metagenomic and 
Metabolomic characterization of fresh perennial ryegrass degradation by rumen Bacteria. Front Microbiol. 2016;7:1854.

5. Emerson EL, Weimer PJ. Fermentation of model hemicelluloses by Prevotella strains and Butyrivibrio fibrisolvens in pure culture and in ruminal enrichment cultures. Appl Microbiol Biotechnol. 2017;101(10):4269-78.

6. Myer PR, Wells JE, Smith TP, Kuehn LA, Freetly HC. Microbial community profiles of the colon from steers differing in feed efficiency. SpringerPlus. 2015;4:454.

7. Mrazek J, Tepsic K, Avgustin G, Kopecny J. Diet-dependent shifts in ruminal butyrate-producing bacteria. Folia Microbiol. 2006;51(4):294-8.

8. Donohoe DR, Garge N, Zhang X, Sun W, O'Connell TM, Bunger MK, Bultman SJ. The microbiome and butyrate regulate energy metabolism and autophagy in the mammalian colon. Cell Metab. 2011;13(5):517-26.

9. Molina L, Giraldo L, Polanco D, Gutierrez L. Cellulolytic and Butyrivibrio fibrisolvens bacteria population density, after supplementing fodder diets (Pennisetum clandestinum). Rev MVZ Cordoba. 2015;20:4947-61.

10. Moreira LR, Filho EX. An overview of mannan structure and mannandegrading enzyme systems. Appl Microbiol Biotechnol. 2008;79(2):165-78.

11. Sewell GW, Aldrich HC, Williams D, Mannarelli B, Wilkie A, Hespell RB, Smith $\mathrm{PH}$, Ingram LO. Isolation and characterization of Xylan-degrading strains of Butyrivibrio fibrisolvens from a Napier grass-fed anaerobic digester. Appl Environ Microbiol. 1988;54(5):1085-90.

12. Dalrymple BP, Swadling Y, Layton I, Gobius KS, Xue GP. Distribution and evolution of the xylanase genes xynA and $x y n B$ and their homologues in strains of Butyrivibrio fibrisolvens. Appl Environ Microbiol. 1999;65(8):3660-7.

13. Lin $\mathrm{LL}$, Thomson JA. An analysis of the extracellular xylanases and cellulases of Butyrivibrio fibrisolvens H17c. FEMS Microbiol Lett. 1991;68(2):197-203.

14. Pollet A, Delcour JA, Courtin CM. Structural determinants of the substrate specificities of xylanases from different glycoside hydrolase families. Crit Rev Biotechnol. 2010;30(3):176-91.

15. Biely P, Singh S, Puchart V. Towards enzymatic breakdown of complex plant xylan structures: state of the art. Biotechnol Adv. 2016;34(7):1260-74.

16. Bosetto A, Justo PI, Zanardi B, Venzon SS, Graciano L, dos Santos EL, Simao Rde C. Research Progress concerning fungal and bacterial beta-Xylosidases. Appl Biochem Biotechnol. 2016;178(4):766-95.

17. Duque E, Daddaoua A, Cordero BF, Udaondo Z, Molina-Santiago C, Roca A, Solano J, Molina-Alcaide E, Segura A, Ramos JL. Ruminal metagenomic libraries as a source of relevant hemicellulolytic enzymes for biofuel production. Microb Biotechnol. 2018;11(4):781-7.

18. Kim JH, Block DE, Mills DA. Simultaneous consumption of pentose and hexose sugars: an optimal microbial phenotype for efficient fermentation of lignocellulosic biomass. Appl Microbiol Biotechnol. 2010;88(5):1077-85.

19. Lin L, Song H, Tu Q, Qin Y, Zhou A, Liu W, He Z, Zhou J, Xu J. The Thermoanaerobacter glycobiome reveals mechanisms of pentose and hexose co-utilization in bacteria. PLoS Genet. 2011;7(10):e1002318.

20. Marounek M, Kopecny J. Utilization of glucose and xylose in ruminal strains of Butyrivibrio fibrisolvens. Appl Environ Microbiol. 1994;60(2):738-9.

21. Snelling TJ, Wallace RJ. The rumen microbial metaproteome as revealed by SDS-PAGE. BMC Microbiol. 2017;17(1):9.

22. Kelly WJ, Leahy SC, Altermann E, Yeoman CJ, Dunne JC, Kong Z, Pacheco DM, Li D, Noel SJ, Moon CD, et al. The glycobiome of the rumen bacterium Butyrivibrio proteoclasticus B316(T) highlights adaptation to a polysaccharide-rich environment. PLoS One. 2010;5(8):e11942.

23. Dunne JC, Li D, Kelly WJ, Leahy SC, Bond JJ, Attwood GT, Jordan TW. Extracellular polysaccharide-degrading proteome of Butyrivibrio proteoclasticus. J Proteome Res. 2012;11(1):131-42.

24. Dunne JC, Kelly WJ, Leahy SC, Li D, Bond JJ, Peng L, Attwood GT, Jordan TW. The cytosolic oligosaccharide-degrading proteome of Butyrivibrio Proteoclasticus. Proteomes. 2015;3(4):347-68.

25. Bond JJ, Dunne JC, Kwan FY, Li D, Zhang K, Leahy SC, Kelly WJ, Attwood GT, Jordan TW. Carbohydrate transporting membrane proteins of the rumen bacterium, Butyrivibrio proteoclasticus. J Proteome. 2012;75(11):3138-44.

26. Caldwell DR, Bryant MP. Medium without rumen fluid for nonselective enumeration and isolation of rumen bacteria. Appl Microbiol. 1966;14(5):794-801.

27. Kopecny J, Zorec M, Mrazek J, Kobayashi Y, Marinsek-Logar R. Butyrivibrio hungatei sp. nov. and Pseudobutyrivibrio xylanivorans sp. nov., butyrateproducing bacteria from the rumen. Int I Syst Evol Microbiol. 2003;53(Pt 1):201-9.

28. Kanehisa M, Sato Y, Morishima K. BlastKOALA and GhostKOALA: KEGG tools for functional characterization of genome and metagenome sequences. J Mol Biol. 2016;428(4):726-31.

29. Gurevich A, Saveliev V, Vyahhi N, Tesler G. QUAST: quality assessment tool for genome assemblies. Bioinformatics (Oxford, England). 2013;29(8):1072-5.
30. Lever M. Carbohydrate determination with 4-hydroxybenzoic acid hydrazide (PAHBAH): effect of bismuth on the reaction. Anal Biochem. 1977;81(1):21-7.

31. Wirth SJ, Wolf GA. Dye-labeled substrates for the assay and detection of CHITINASE and lysozyme activity. J Microbiol Methods. 1990;12(3-4):197-205.

32. Bidochka MJ, Tong Kl, Khachatourians GG. Partial purification and characterization of two extracellular N-acetyl-D-glucosaminidases produced by the entomopathogenic fungus Beauveria bassiana. Can J Microbiol. 1993;39(1):40-5.

33. Bradford MM. A rapid and sensitive method for the quantitation of microgram quantities of protein utilizing the principle of protein-dye binding. Anal Biochem. 1976;72:248-54.

34. Laemmli UK. Cleavage of structural proteins during the assembly of the head of bacteriophage T4. Nature. 1970;227(5259):680-5.

35. Flint HJ, Zhang JX, Martin J. Multiplicity and expression of xylanases in the rumen CELLULOLYTIC bacterium ruminococcus-flavefaciens. Curr Microbiol. 1994;29(3):139-43.

36. Shevchenko A, Tomas H, Havlis J, Olsen JV, Mann M. In-gel digestion for mass spectrometric characterization of proteins and proteomes. Nat Protoc. 2006;1(6):2856-60.

37. Rappsilber J, Mann M, Ishihama Y. Protocol for micro-purification, enrichment, pre-fractionation and storage of peptides for proteomics using StageTips. Nat Protoc. 2007;2(8):1896-906.

38. Ost'adal M, Eckhardt A, Herget J, Miksik I, Dungl P, Chomiak J, Frydrychova M, Burian M. Proteomic analysis of the extracellular matrix in idiopathic pes equinovarus. Mol Cell Biochem. 2015;401(1-2):133-9.

39. Gao X, Zhang Z, Zhang Y, Li Y, Zhu H, Wang S, Li C. A newly determined member of the meso-Diaminopimelate dehydrogenase family with a broad substrate Spectrum. Appl Environ Microbiol. 2017:83(11):1-10.

40. Verhees $\mathrm{CH}$, Huynen MA, Ward DE, Schiltz E, de Vos WM, van der Oost J. The phosphoglucose isomerase from the hyperthermophilic archaeon Pyrococcus furiosus is a unique glycolytic enzyme that belongs to the cupin superfamily. J Biol Chem. 2001;276(44):40926-32.

41. Loessner MJ, Wendlinger G, Scherer S. Heterogeneous endolysins in listeria monocytogenes bacteriophages: a new class of enzymes and evidence for conserved holin genes within the siphoviral lysis cassettes. Mol Microbiol. 1995;16(6):1231-41.

42. Kimmel $\lrcorner$, Reinhart GD. Reevaluation of the accepted allosteric mechanism of phosphofructokinase from Bacillus stearothermophilus. Proc Natl Acad Sci U S A. 2000;97(8):3844-9.

43. Yon JM, Desmadril M, Betton JM, Minard P, Ballery N, Missiakas D, S G-M, Perahia D, Mouawad L. Flexibility and folding of phosphoglycerate kinase. Biochimie. 1990:72(6-7):417-29.

44. Taylor RC, Brown AK, Singh A, Bhatt A, Besra GS. Characterization of a betahydroxybutyryl-CoA dehydrogenase from mycobacterium tuberculosis. Microbiology (Reading, England). 2010;156(Pt 7):1975-82.

45. Thomson GJ, Howlett GJ, Ashcroft AE, Berry A. The dhnA gene of Escherichia coli encodes a class I fructose bisphosphate aldolase. Biochem J. 1998;331(Pt 2):437-45

46. Schwartzbach CJ, Spremulli LL. Bovine mitochondrial protein synthesis elongation factors. Identification and initial characterization of an elongation factor Tu-elongation factor Ts complex. J Biol Chem. 1989;264(32):19125-31.

47. Fillinger S, Boschi-Muller S, Azza S, Dervyn E, Branlant G, Aymerich S. Two glyceraldehyde-3-phosphate dehydrogenases with opposite physiological roles in a nonphotosynthetic bacterium. J Biol Chem. 2000;275(19):14031-7.

48. Hermann KER. Shikimate pathway: aromatic amino acids and beyond. In: Encyclopedia of Life Sciences; 2001.

49. Yeoman CJ, Kelly WJ, Rakonjac J, Leahy SC, Altermann E, Attwood GT. The large episomes of Butyrivibrio proteoclasticus B316T have arisen through intragenomic gene shuttling from the chromosome to smaller Butyrivibriospecific plasmids. Plasmid. 2011;66(2):67-78.

50. Utt EA, Eddy CK, Keshav KF, Ingram LO. Sequencing and expression of the Butyrivibrio fibrisolvens xylB gene encoding a novel bifunctional protein with beta-D-xylosidase and alpha-L-arabinofuranosidase activities. Appl Environ Microbiol. 1991:57(4):1227-34

51. Williams AG, Withers SE. The regulation of xylanolytic enzyme formation by butyrivibrio-fibrisolvens NCFB-2249. Lett Appl Microbiol. 1992;14(5):194-8.

52. Lama L, Calandrelli V, Gambacorta A, Nicolaus B. Purification and characterization of thermostable xylanase and beta-xylosidase by the thermophilic bacterium Bacillus thermantarcticus. Res Microbiol. 2004;155(4):283-9.

53. Grootaert C, Delcour JA, Courtin CM, Broekaert WF, Verstraete W, Van de Wiele T. Microbial metabolism and prebiotic potency of arabinoxylan 
oligosaccharides in the human intestine. Trends Food Sci Technol. 2007; 18(2):64-71.

54. Jeffries TW. Utilization of xylose by bacteria, yeasts, and fungi. Adv Biochem Eng Biotechnol. 1983;27:1-32.

55. McMillan JD. Xylose fermentation to ethanol. Enzymatic conversion of biomass for fuels production, vol. 599; 1994.

56. Palevich NKWJ, Ganesh S, Rakonjac J, Attwood GT. Butyrivibrio hungatei MB2003 competes effectively for soluble sugars released by Butyrivibrio proteoclasticus B316T from growth on xylan or pectin. bioRxiv. 2019;85(3):1-19.

57. Zhong Y, Xue M, Liu J. Composition of rumen bacterial Community in Dairy Cows with Different Levels of somatic cell counts. Front Microbiol. 2018;9:3217.

58. Hart EH, Creevey CJ, Hitch T, Kingston-Smith AH. Meta-proteomics of rumen microbiota indicates niche compartmentalisation and functional dominance in a limited number of metabolic pathways between abundant bacteria. Sci Rep. 2018;8(1):10504

59. Badalato N, Guillot A, Sabarly V, Dubois M, Pourette N, Pontoire B, Robert P, Bridier A, Monnet V, Sousa DZ, et al. Whole proteome analyses on Ruminiclostridium cellulolyticum show a modulation of the Cellulolysis machinery in response to cellulosic materials with subtle differences in chemical and structural properties. PLoS One. 2017;12(1):e0170524.

Ready to submit your research? Choose BMC and benefit from:

- fast, convenient online submission

- thorough peer review by experienced researchers in your field

- rapid publication on acceptance

- support for research data, including large and complex data types

- gold Open Access which fosters wider collaboration and increased citations

- maximum visibility for your research: over $100 \mathrm{M}$ website views per year

At $\mathrm{BMC}$, research is always in progress.

Learn more biomedcentral.com/submissions 